\title{
True double aortic lumen in tetralogy of Fallot
}

\author{
Antonio J. Marinho-da-Silva*, Antonio M. Sá-e-Melo, Luis A. Providência \\ Pediatric Cardiology, Department of Cardiology, University Hospital, P. Mota Pinto, 3049 Coimbra codex, Portugal
}

Received 18 September 1997; received in revised form 31 October 1997; accepted 31 October 1997

\begin{abstract}
In an infant with tetralogy of Fallot submitted to angiographic study, a double aortic lumen was found. Although no particular complaints were related to the additional abnormality, we report this case to emphasize the possibility of occurrence of persistent embryonic fifth aortic arch. (C) 1998 Elsevier Science Ireland Ltd
\end{abstract}

Keywords: Double aortic lumen; Tetralogy of Fallot

\section{Introduction}

Double lumen aortic arch is a rare abnormality corresponding most probably to persistence of the embryonic fifth arterial arch [1-3]. In certain circumstances this anomaly can be of great clinical and pathological importance and is, unfortunately, frequently misdiagnosed [2]. To our knowledge there is only one reported case associated to tetralogy of Fallot [2]. In order to contribute to a better understanding of the anomaly, we describe a new case detected during pre-operative angiographic study of an infant.

\section{Case report}

A 7-month-old boy born of an uneventful pregnancy was referred to us because of cyanotic spells. Physical examination showed a 7.6-kg infant severely

\footnotetext{
*Corresponding author
}

cyanotic, without any special dysmorphism. A single second heart sound preceded by a grade I/VI ejection murmur could be heard at the time. Normal peripheral pulses and blood pressure were present as well. Right ventricle hypertrophy, with upright $\mathrm{T}$ wave in VI was seen on the electrocardiogram. A chest radiograph showed marked pulmonary oligoemia without cardiomegaly. Doppler echocardiography demonstrated a narrowed right outflow tract anterocephalically deviated and a large subaortic ventricular septal defect. Right-to-left shunt was present together with a right ventricle to pulmonary artery gradient of $72 \mathrm{mmHg}$. Cardiac catheterization and angiography was carried out without complications. An aortic oxygen saturation of $74 \%$ and systemic pressure in the right ventricle of $96 \mathrm{mmHg}$ were both measured. Left ventriculography using left anterior oblique projection with cranio-caudal tilt confirmed the Fallot anatomy and also showed a duplication of the aortic lumen (Fig. 1). No particular consequences could be demonstrated related to the double lumen. Total correction was done with complete success, and the 

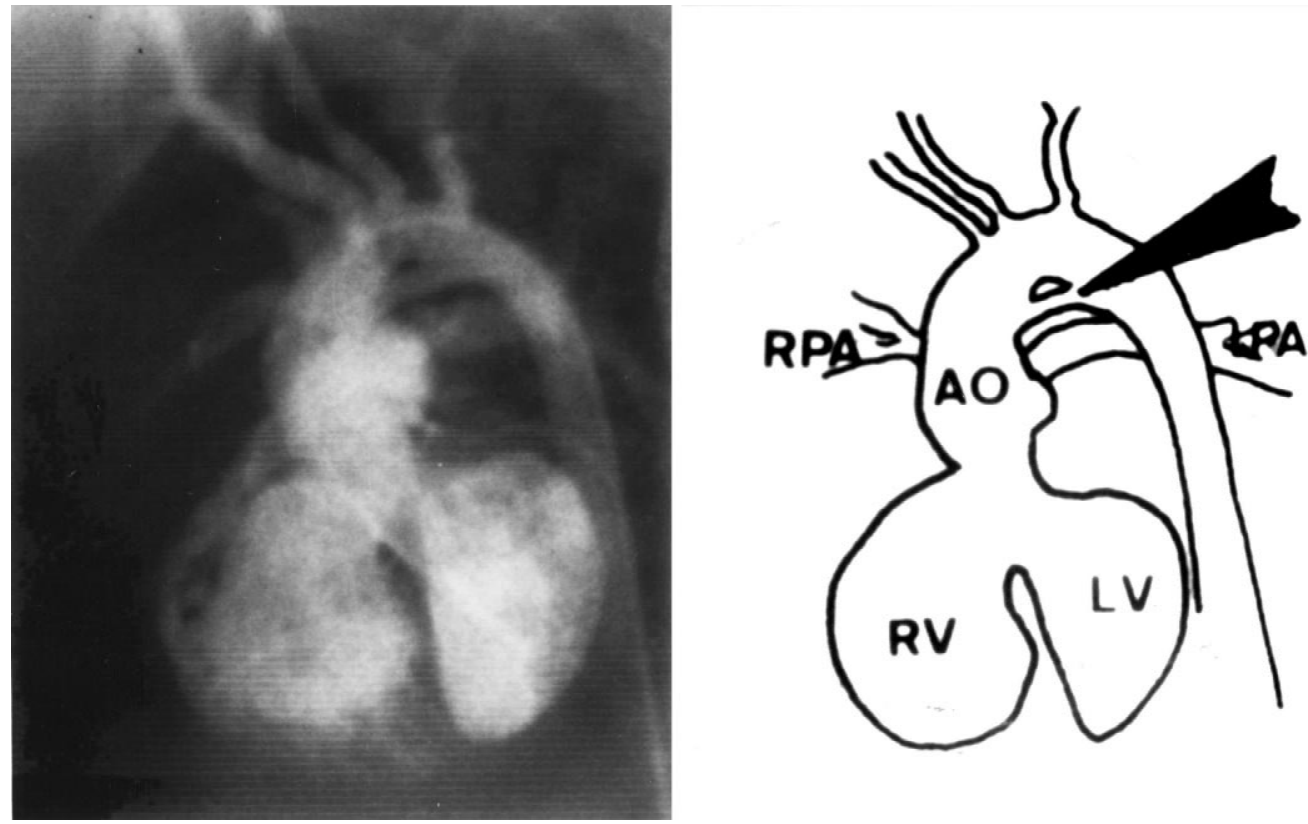

Fig. 1. Left ventriculography showing typical Fallot anatomy and the inferior aortic pathway (arrow), corresponding to true double aortic lumen. AO, aorta; LPA, left pulmonary artery; RPA, right pulmonary artery; LV, left ventricle; RV, right ventricle.

child is now living a completely normal life without any relevant sequelae.

\section{Discussion}

True double aortic lumen describes a systemic-tosystemic connection between distal ascending and proximal descending aortic arch. This particular vessel arrangement supports the idea of embryonic fifth aortic arch persistence as a good explanation for the anomaly (Fig. 2). Despite some controversy, however, the presence of a systemic-to-pulmonary connection is also possible, where persistent fifth aortic arch connects the ascending aorta to the embryonic sixth arch [2]. In complex cyanotic cardiopathies, such as pulmonary atresia with ventricular septal defect, this special connection can be of great importance as a blood supplier to the lungs [4]. So its recognition is important in order to allow distinction from significant aortic collateral or an arterial duct. Interrupted aortic arch or other obstructive lesions, where distal flow can be dependent from such a channel, are of similar clinical importance [2]. In our case, no function could be attributed to the double lumen, despite a severe form of tetralogy of Fallot, and in this perspective we describe an important curiosity. Moreover, we think that describing this abnormality can contribute to a better evaluation of

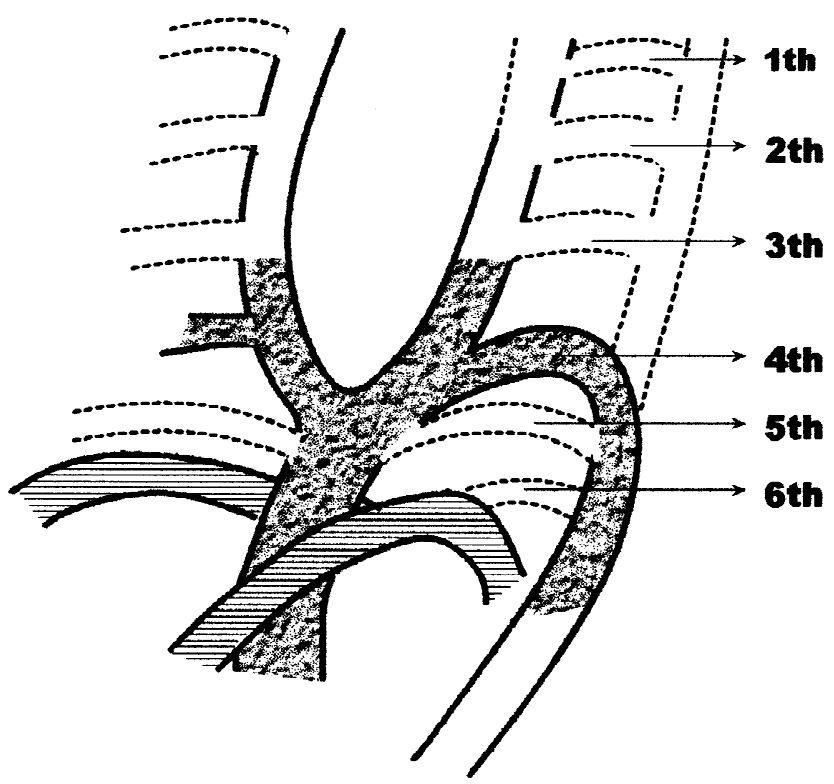

Fig. 2. Drawing of the embryonic aortic arch showing the possibility of true double aortic lumen to be the expression of persisting fifth aortic arch: 1-6, embryonic archs; 4th arch, embryonic aorta; 5th arch, double aortic lumen; 6th arch, embryonic pulmonary artery and ductus arteriosus. 
cardiopathies of great complexity, and eventually to the prevention of unnecessary surgery.

\section{References}

[1] Van Praagh R, Van Praagh S. Persistent fifth arterial arch in man. Congenital double lumen aortic arch. Am J Cardiol 1969;24:27982 .
[2] Gerlis LM, Ho SY, Anderson RH, Da Costa P. Persistent 5th aortic arch-a great pretender: three new covert cases. Int J Cardiol 1989;23:239-47.

[3] Herrera MA, D'Souza VJ, Link KM, Weesner KM, Formanek AG. A persistent fifth aortic arch in man: a double lumen aortic arch. Presentation of a new case and a review of the literature. Pediatr Cardiol 1987;8:265-9.

[4] Macartney F, Scott O, Deverall PB. Haemodynamic and anatomical characteristics of pulmonary blood supply in pulmonary atresia with ventricular septal defect-including a case of persistent fifth aortic arch. Br Heart J 1974;36:1049-60. 